Session 1139

\title{
Introducing Engineering Economy Students to Real Options
}

\author{
Eyler R. Coates, S. Kant Vajpayee, Jon Juneau \\ University of Southern Mississippi/Engineering Consultant \\ Box 5137, Hattiesburg, MS 39406
}

\begin{abstract}
Engineering economy has been a core requirement in engineering curriculums for many years. The traditional engineering economy courses only include problems with all deterministic inputs, even though deterministic data seldom occur in business. Also, traditional net present value methods make no allowance for flexibility by management and assume a static environment. The analysis of stochastic engineering economic problems has been ignored and the technological changes over the past 15 years have not been fully utilized in the traditional engineering economy courses. Therefore, students are not proficient to do such analyses when working in the business world. This paper demonstrates the ease that engineering economy problems with stochastic input variables and real options can be simulated with simulation software that is readily available to students on personal computers. The novel application presented in this paper will greatly enhance both Engineering Economy and Simulation courses.
\end{abstract}

\section{Introduction}

In order to deal with the variability issues of real business projects, risk analysis is necessary. But, the risk analysis approach is one aspect of economic analyses that is commonly ignored during project evaluations. Ristroph points out that errors in estimates of cash flows are the rule rather than the exception. He also states that the primary question involving most cash flows is not whether they will be correct, but rather by how much will they be incorrect. ${ }^{12}$ Including risk analyses in engineering economy solutions is an important step for acquiring more information to make better management decisions. Ho and Pike report that "proponents of risk analysis argue that increased risk information improves management's understanding of the nature of risks, helps identify the major threats to project profitability and reduces forecasting errors." 9 They also report that "the risk analysis approach provides useful insights into the project, improves decision quality and increases decision confidence." 9 The methods for risk analysis of projects have been published for a long time and the availability of computers and software is pervasive. Given that the capabilities of doing risk analyses are available, Goyal et al. has questioned why there is so little exposure to the stochastic nature of project cash flows and other project variables in undergraduate curricula. ${ }^{5}$ 
There are several approaches used to handle economic risk. One approach is scenario analysis. However, as Park has pointed out, worst-case and best-case scenarios are not easy to interpret and do not provide probabilities of occurrence of those possibilities nor do they normally provide additional information such as the probability of losing money on a project or the probability of other possibilities. ${ }^{11}$ Sensitivity analysis and spider plots can provide insight into an engineering economy problem but are not appropriate when there is statistical dependence between variables. ${ }^{3}$ Probability descriptions of input variables allow further refinement of the analysis of economic risk and allow the output of a distribution for the desired answer.

The notion of probability distributions to describe economic risk has been around for many years. Hillier, in his groundbreaking paper in 1963, proposed the use of probability distributions of present worth to properly convey project risk information. ${ }^{8} \mathrm{He}$ also demonstrated that the probability distribution of present worth or annual worth or internal rate of return could under certain assumptions be derived when the cash flows were mutually independent random variables. Later, Giaccotto derived the distribution parameters for the NPV when the cash flows were correlated by a first order autoregressive stochastic process (or a Markov process). ${ }^{4}$ As projects become complicated, derivations of the probability distribution of the NPV as a function of the unknown random input variables can be tedious or impossible. ${ }^{13}$ For these cases, computer simulation makes sense.

The use of simulation software makes engineering economy problem solutions more realistic. As Ristroph states, simulation provides insight into the variability of a project's potential performance and hence its risk, so that an informed, albeit subjective, decision can be made. ${ }^{12}$ Simulating the problem effectively deals with the variability issues of real business problems. Probability descriptions of input variables and Monte Carlo sampling together provide a practical method of finding the distribution of the desired output given the various random and deterministic input variables. This technique allows a further refinement of the analysis and allows the output of a distribution for the desired answer. Table 1 (from [12]) illustrates the differences between Hillier's approach and a simulation approach for solving 'real' engineering economy problems.

Given that we have imperfect information when we make a financial decision, we need to determine what happens when the information becomes certain as the project progresses. Is there an option to bail out of a bad deal or is the organization committed to finishing a project? If the organization can "cut its losses" and perhaps recoup some losses by recovering some of its investment in the event that a project goes sour, then the organization has some flexibility in regards to the execution of the project. In other words, there is an "option" for an alternative project direction once the project is underway.

Introduction To Real Options

The ability to adjust a project gives an organization real options. Recently, the evaluation of real options has begun to use the methods developed for evaluating financial options. For example, deciding to prematurely abandon a project can be modeled as a put option on a stock. 
Table 1. Differences between Hillier's Approach and A Simulation Approach to Solving Engineering Economy Problems

\begin{tabular}{|l|l|}
\hline Hillier's Approach & Simulation Approach \\
\hline $\begin{array}{l}\text { Variable cash flows; } \\
\text { year to year flows are } \\
\text { independent }\end{array}$ & $\begin{array}{l}\text { cash flows can be } \\
\text { independent or } \\
\text { dependent }\end{array}$ \\
\hline $\begin{array}{l}\text { theoretical } \\
\text { distributions which are } \\
\text { independent }\end{array}$ & $\begin{array}{l}\text { cash flows can be } \\
\text { theoretical or } \\
\text { empirical data }\end{array}$ \\
\hline $\begin{array}{l}\text { end of year } \\
\text { conventions }\end{array}$ & $\begin{array}{l}\text { timing of cash flows } \\
\text { can be at any point }\end{array}$ \\
\hline $\begin{array}{l}\text { Enhancement: First } \\
\text { year's cash flow is } \\
\text { independent and } \\
\text { remaining cash flows } \\
\text { are dependent }\end{array}$ & $\begin{array}{l}\text { All input variables can } \\
\text { be correlated with } \\
\text { other variables or } \\
\text { auto-correlated }\end{array}$ \\
\hline \multicolumn{2}{|l}{} \\
\hline
\end{tabular}

\section{Stock Options}

An option is a contract between the option writer, who sells the option, and the option owner, who buys the option. If the option owner decides to exercise the option, the option writer must execute the transaction specified in the contract. Since the option contract can be bought and sold, they have a market value. The factors that determine the value of an option include the price of the publicly traded stock and the specifics of the option.

To introduce the ideas of stock options, assume that XYZ corporation has publicly traded stock and stock options. An option on XYZ corporation's stock would specify an exercise price (or strike price) and an expiration date. The exercise price is the cost to the option owner to exercise the contract. The expiration date is the last date that the owner can exercise the option.

Calls and puts are the two types of stock options. A call option on XYZ stock might have an exercise price of 100 and an expiration date of July 20. This option would allow the owner to buy XYZ stock from the option writer for 100 dollars per share on or before July 20. (Note: European options can only be exercised on the expiration date and American options can be exercised on or before the expiration date. We assume here that the option is an American option.) The owner of an American put option on XYZ stock with an exercise price of 100 and an expiration date of July 20 can sell XYZ stock for 100 dollars on or before July 20. The put option writer would be required to buy XYZ stock for 100 dollars. Stock options have an intrinsic value. To figure out the intrinsic value of a call option, consider the XYZ call option described above. We will relate its intrinsic value to the market value of the underlying asset, the shares of XYZ corporation stock. If the market price of the stock is 125 dollars and the call 
option owner wanted XYZ stock, they would rather buy the stock for 100 dollars (option exercise price) instead of the market price of 125 dollars. Since the stock bought for 100 dollars by exercising the call option could be sold immediately at the market price of 125 dollars giving an immediate profit of 25 dollars, the intrinsic value of the option would be 25 dollars. If the stock of XYZ corporation stock has a market price of 85 dollars, the option to buy XYZ stock for 100 dollars would have zero intrinsic value, because buying XYZ stock for 100 dollars when it is available for 85 dollars is irrational.

The intrinsic value of a put option can be determined for the above situations. For example, consider a put option on XYZ stock with an exercise price of 100 dollars. The owner of this option has the right to sell XYZ stock for 100 dollars. If the market price of XYZ stock is 85 dollars, the owner could buy the stock for 85 dollars and then exercise the option to receive 100 dollars making an instant profit of 15 dollars. Therefore, the intrinsic value of this put option would be 15 dollars. If the market price of XYZ stock is 125 dollars, then the put option would not be profitable to exercise and the intrinsic value would be zero. A stock option that has a positive intrinsic value should always be exercised before it expires, otherwise it will become worthless.

Because of the possibility for large profits, a great deal of work has been done to learn methods to value options. On the expiration date, an option's value will equal its intrinsic value, with no uncertainty. The European option is the easiest to evaluate because it can only be exercised on the expiration date. The value of the European option before expiration involves adjustments for both the time value of money and the uncertainty in the final stock price. An analysis on a binomial lattice is used when the situation is modeled with a discrete time periods and discrete changes in price. The Black-Scholes formula for the European call option is the continuum limit, with the time periods and the price changes becoming very small, of a binomial lattice. Brealy and Meyers hint at how to adjust the value of the European call to determine the value of other options. ${ }^{1}$ When the methods of evaluating financial options are applied to the choices an organization makes in a project, the value for real options can be approximated.

Simple Real Options

If an organization can show that their choices, or the real options, are similar to financial options, then they can use the financial option evaluation methods to evaluate the real options. Since real options are often more complicated than the European call option, simulation should be a powerful tool for evaluating real options. In this paper, simulation is used to evaluate an organization's real option to prematurely abandon a project because expectations are not being met.

The option to abandon is often modeled like a put option. When the organization decides to abandon a project, they might sell their capital equipment investment. The cash flow from this sale could be modeled as the exercise price of the put option. Note: The organization might also have the real option to expand their production capability if expectations are better than expected. This could be analyzed like a call option with the exercise price being the amount that required investment for the expansion. However, in this paper, only the option to abandon (the put option) will be modeled. 
The next sections will demonstrate the ease that the more complex engineering economy problems with stochastic input variables can be simulated with simulation software

\section{Example Problem}

The problem presented in this paper is a three-phase project with incoming cash flows in each phase and an option of abandoning the project at the end of the first two phases. This type of problem is becoming more prevalent in today's business because projects are becoming more and more complex, longer in duration and more costly. Most companies cannot afford to financially back a long-term project without receiving some feedback (cash flows) spread throughout the duration of the project.

Below is the description of the problem presented in this paper: A company has a project that requires a $\$ 30,000$ investment. The $\$ 30,000$ investment is the best estimate but there is an uncertainty about the amount. The company's minimum attractive rate of return (MARR) can be calculated based on the capital structure of the firm using the weighted-average cost of capital. ${ }^{11}$ The degree of project variability will be captured by the probability distributions of the cash flows and the timing. So, the discount rate can be set to the risk-free rate. For our example, we are using $i=15 \%$. Each phase of the project could have a duration between 1 and 2 years and incoming cash flows for each phase is estimated to be $\$ 15,000$. From past experience, the company knows that the estimated cash flows are somewhat variable and that are also correlated to each other (a typical time series). That is, if the first cash flow is low, then the remaining cash flows are also likely but not necessarily low. Could the company loose money doing this project?

The solution to this problem using end-of-year cash flow conventions yields a risky answer because traditional engineering economy analysis is not designed to handle variable progress payments and the other uncertain parts. The method presented in this paper provides an easy way to solve this more complex problem using simulation software. Simulation software can estimate the distribution of the possible net present values (NPV) for the project. Arena, a readily available PC based simulation software, was used to solve this problem. The authors recommend the following steps when using simulation software to solve this type of economic decision problem:

1. Determine the input variables

2. Create a flowchart for a single scenario

3. Identify the entity for the simulation

4. Determine the appropriate attributes and global variables that are required for the final result

5. Design and enter the network diagram to generate multiple scenarios according to the flowchart

6. Verify the model

7. Run the simulation

8. Analyze the output

Each of the above steps is described in the following solution. 
The given data for this problem are the distributions for the initial investment, discounting rate, the cash flows at the completion of each phase and the duration of each phase of the project.

Step 1 - Determine input variables

The simulation solution requires that we input the initial investment, the minimum attractive rate of return (i.e., the discounting rate), the amounts of the individual progress payments, the timing of these progress payments, the project deadline and the late penalty for missing the deadline. The values of all of these inputs can be deterministic or stochastic according to the requirements of the problem. For this problem, the initial investment by the company to begin the project is estimated to be normally distributed with a mean of $\$ 30,000$ and a standard deviation of $\$ 333$, denoted in this paper as $\operatorname{NORM}(30000,333)$. Given that plus or minus three standard deviations in a normal distribution tend to encompass $99.73 \%$ of the possible data points, essentially it is assumed that the investment will be likely be around $\$ 30,000$ but could even be as low as $\$ 29,000$ and as high as $\$ 31,000$ dollars. Likewise, the cash flow at the completion of the first is $\operatorname{NORM}(15000,2000)$ dollars and the duration of each phase of the project is estimated to be $\operatorname{NORM}(1.5,0.2)$ years. The time duration is given in years to match the time units of the discount rate, which is $15 \%$ per year. Note that unique cash flows and time durations could easily be assumed for each phase. The details on how to determine what distributions to use for a variable are covered in Coates and Endt. ${ }^{2}$

Note that the cash flows for the last 2 phases follow a first-order auto-correlated series based upon the first cash flow. For this example we will assume an $80 \%$ correlation coefficient although this figure should be based on past experience. So this means that if the first cash flow is low, then the remaining cash flows are likely (but not necessarily) to be low also and the management might decide to abandon the project.

Step 2 - Create flowchart

A good intermediate step to solving the overall problem is to generate a flowchart for calculating an individual scenario. The flowchart for this problem is shown in Figure 1. Once the basic steps to generate a single scenario are worked out, the transition to a simulation flowchart is rather simple.

Step 3 - Identify entity

Each entity, in the simulation run, will represent a single replication (scenario) of the net present value calculation. After an entity is created, the stochastic variables are selected via sampling from the appropriate distribution.

Step 4 - Determine attributes and global variables

Several variables are needed in order to calculate the net present value for an individual scenario. These would be assigned as attributes since they would be unique to a scenario (entity). From the flowchart in Figure 1, these attributes would be Interest, Investment, Timing, Payment and NPV.

The auto-correlation of $80 \%$ is "hard-wired" into the calculations. It could also have been a global variable. 


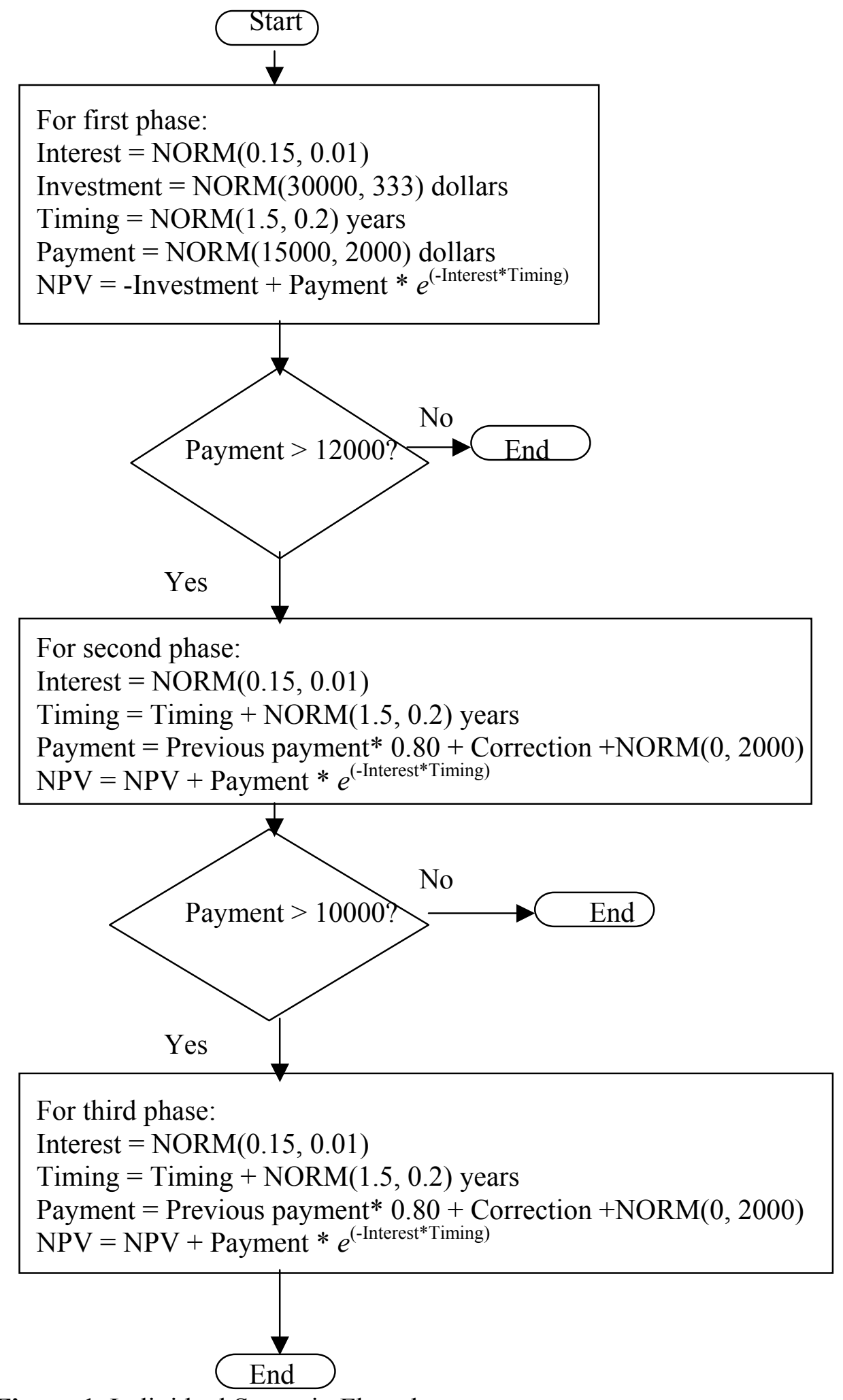

Figure 1. Individual Scenario Flowchart 
Step 5 - Design and enter the network diagram

There is almost a one-to-one relationship between the Arena simulation network diagram and the flowchart given in Figure 1. The simulation network is rather elegant and well within the grasp of the average student.

The Arrive module, labeled New Scenario, allows for the creation of entities. Each entity represents one scenario. Detail of the Arrive Module is given in Figure 2.

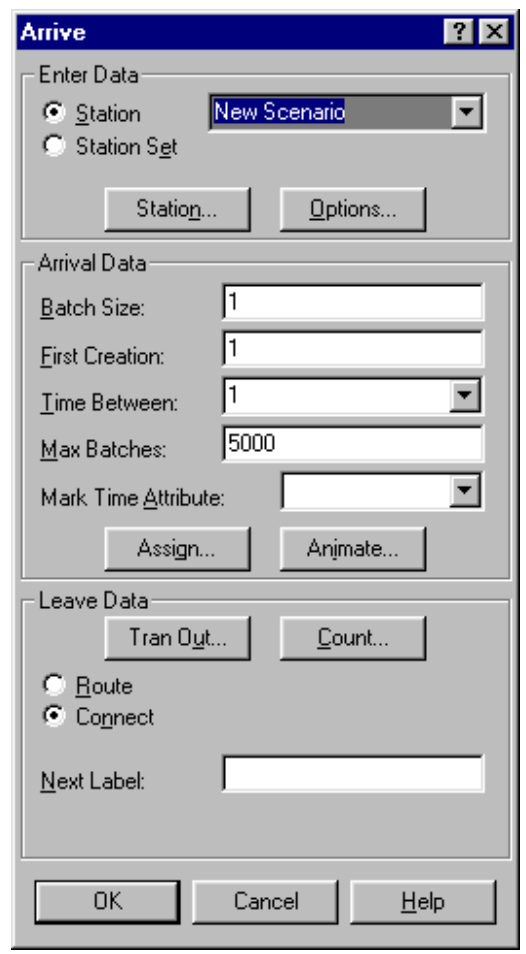

Figure 2. Detail of Arrive Module

The Actions Modules perform the iterative calculations to generate the value of the NPV attribute. The first phase Action Module calculates the NPV up to the point of the first progress payment. The details for that module are given in Figure 3. The details of the other action modules for the remaining progress payments are very similar to Figure 3.

The Depart module allows the attribute NPV to be tallied before the entity is destroyed. The Arena network requires two additional modules. The Simulate module is required only to enter the title of the report and the name of the analyst. The Statistics module is required to tell the simulation software to save the output data, namely NPV, into a file for later analysis. There are several methods for stopping the simulation. The method chosen was to limit the number of created entities in the Arrive module. For this example, the number of entities (scenarios) was 5000. See Figure 2. 
Step 6 - Verify the model

There are a couple of ways to verify this simulation model. A relatively easy method is to replace all the stochastic variables with constants. Then run the simulation program (only one scenario is needed). Compare the results with a manual calculation. For this problem, using all deterministic inputs such as the means of the distributions yields and allowing no flexibility to terminate the project yields a point estimate of $-\$ 821$. This is verified by the manual NPV calculation, which yields a point estimate of a negative $\$ 820.49$.

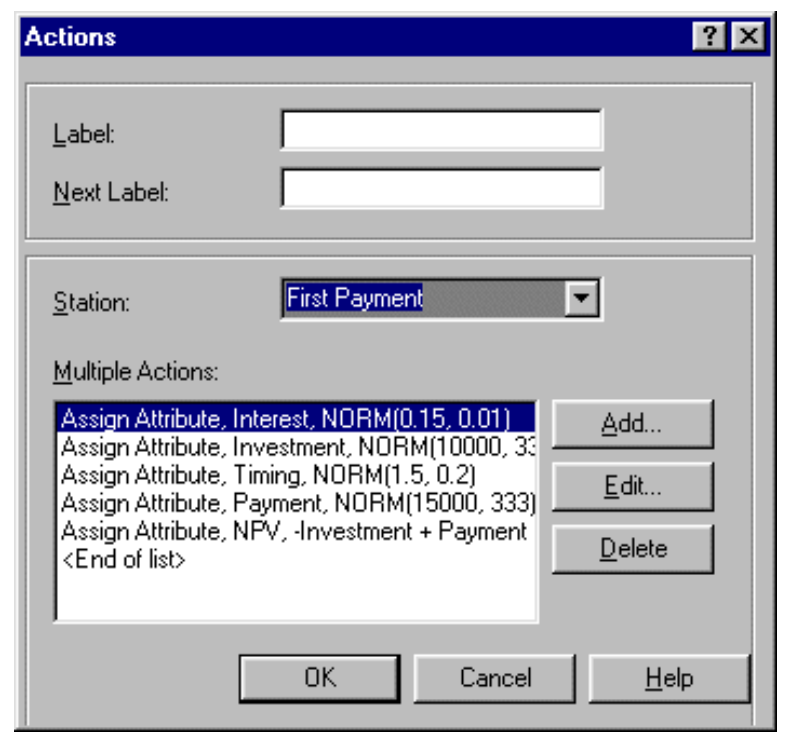

Figure 3. Detail of Action Module for First Phase

Step 7 - Run the simulation

The NPV associated with the particular scenario (entity) is calculated from the cash flows from all 3 phases of the project. This NPV is stored as an attribute of the entity. Before the entity leaves the system, the NPV is collected as a statistic and tabulated by the simulation software. Five thousand scenarios are run by the simulation program. It only takes 0.05 minutes to run the simulation. Thus, the number of scenarios can be increased greatly with little strain on computer resources.

Step 8 - Analyze the output

The text output of the simulation program is given in Figure 4. Because each entity was created one time unit apart, the current time on the Arena report also reflects the number of replications in the study (5000). The output reporting capabilities of simulation packages are used to advantage here. Summary statistics are automatically generated. One can see that the net present value of the 5000 scenarios ranges from $\$ 4274.6$ to $\$ 24,546$. A histogram from the output is given in Figure 5. Based on the histogram, the student can determine any prediction (tolerance) interval. For example, it appears that the middle $90 \%$ of the observations fall between $\$ 16,000$ and $\$ 21,000$. This means there is a $90 \%$ confidence that the net present value of this project falls between $\$ 16,000$ and $\$ 21,000$. Therefore, it would be highly improbable for the company to loose money on this project. From the text output, one can obtain the mean expected value of $\$ 19,055$. Incidentally, if we had used deterministic estimates of the input values and no 
allowance for flexibility to cancel the project (a real option), the NPV calculation would yield a point estimate of $-\$ 820.49$ with no indication whatsoever of the probable range of the risk associated with this project.

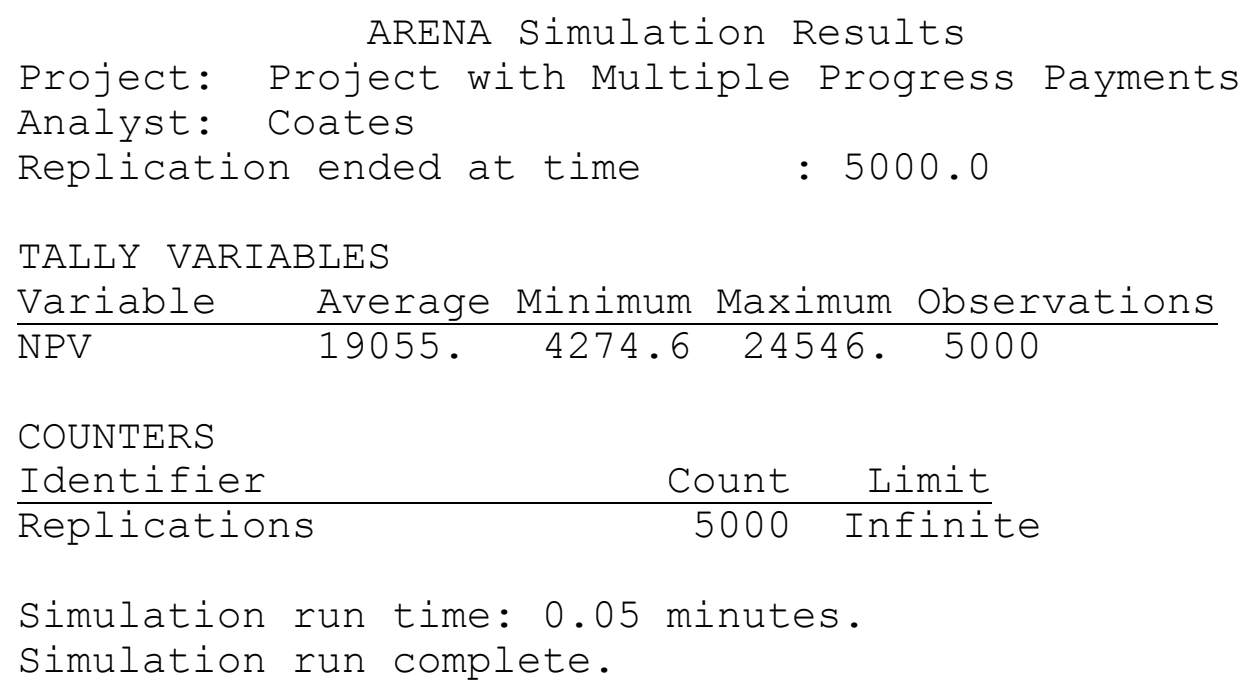

Figure 4. Text Output of the simulation program

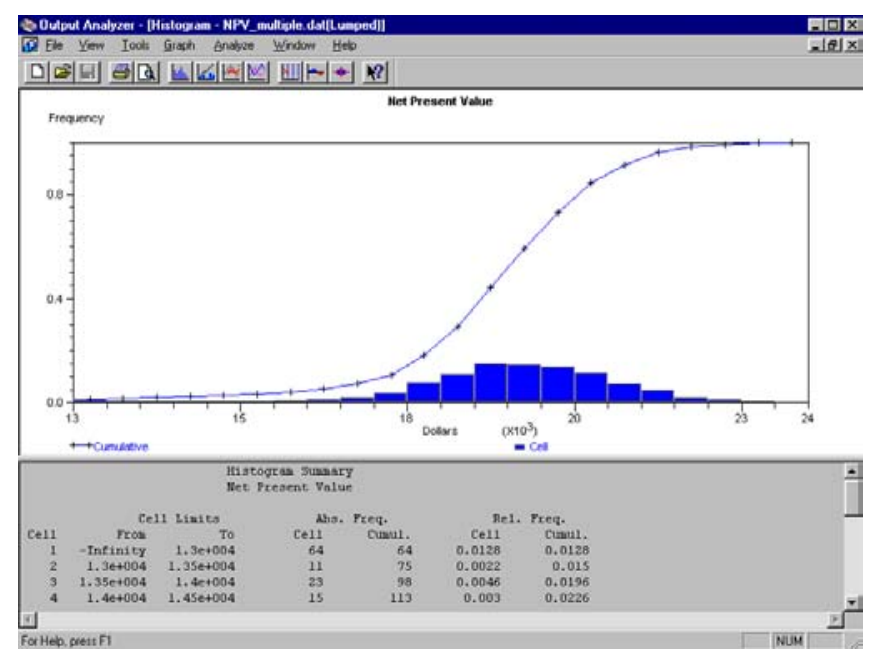

Figure 5. Histogram of the output

\section{Conclusion}

This paper demonstrated that commonly available simulation software can:

- easily be used in engineering economy problems to explain the risk associated with a project

- give the present worth distribution of a project when there is uncertainty about the future timing of cash flows, particularly in those projects that have progress payments which involves the uncertainty of the amount of the cash flows, an uncertain interest rate as well as uncertain timing. 
- easily incorporate a discontinuous function a decision to cancel a poor performing project (a real option)

- handle problems with a number of replications that that can not be handled by spreadsheet software

The example presented in this paper could be used in an engineering economy course showing how risk analyses and real options that react to the ongoing project performance can be handled realistically using simulation software. The example problem could also be used as additional novel applications in a simulation course. When students are exposed to these methods at the undergraduate level, they will carry these practices into the work place and advance the accuracy of decision making.

\section{Areas of Future Research}

When should an organization decide to exercise their real option? This is particularly interesting since one often assumes that the organization decides from an improved forecast of the future, after they obtain more information. How can someone use history to predict the future better if the state has not changed? In this paper, the authors used a simple cutoff values for the cash flow at each phase to decide whether to proceed with the project. Herath and Park suggest investigating the use of Bayesian approaches to making the decision. ${ }^{7}$ The authors hope to investigate this in the future.

\section{Bibliography}

1. Brealy, R.A. and Myers, S.C., [2000], Principles of Corporate Finance, 6th Edition, Irwin McGraw-Hill.

2. Coates, E.R., and Endt, R.L., Making Engineering Economy 'Real' With Simulation Software, Proceedings of the 2000 ASEE Annual Conference - St. Louis, MO, June, 2000.

3. Eschenbach, T.G., and R.J. Gimpel, [1990], Stochastic Sensitivity Analysis, The Engineering Economist, 35(4), 305-321.

4. Giaccotto, C., [1984], A Simplified Approach To Risk Analysis In Capital Budgeting With Serially Correlated Cash Flows, The Engineering Economist, 29(4), 273-286.

5. Goyal, A.K., J.M. Tien, and P.A. Voss, [1997], Integrating Uncertainty Considerations In Learning Engineering Economy, The Engineering Economist, 42(3), 249-257.

6. Herath, S.B.H., and C.S. Park, [1999], Economic Analysis of R\&D Projects: An Options Approach, The Engineering Economist, 44(1), 1-35.

7. Herath, S.B.H., and C.S. Park, [2000], Exploiting Uncertainty: Investment Opportunities as Real Options: A New Way of Thinking in Engineering Economics, The Engineering Economist, 45(1), 1-36.

8. Hillier, F.S., [1963], The Derivation of Probabilistic Information For The Evaluation Of Risky Investments, Management Science, 1963, 443-457.

9. Ho, S.S.M., and R.H. Pike, [1998], Organizational Characteristics Influencing The Use Of Risk Analysis In Strategic Capital Investments, The Engineering Economist, 43(3), 247-268. 
10. Nembhard, H.B., Shi, L., and C.S. Park, [2000], Real Option Models for Managing Manufacturing System Changes in the New Economy, The Engineering Economist, 45(3), 232-258.

11. Park, C.S., [2002], Contemporary Engineering Economics, $3^{\text {rd }}$ Edition, Prentice Hall, Upper Saddle River, New Jersey.

12. Ristroph, J.H., Economic Simulations for Risk Analysis, Proceedings of the 2000 ASEE Annual Conference St. Louis, MO, June, 2000.

13. Seila, A.F., and J. Banks, [1990], Spreadsheet Risk Analysis Using Simulation, Simulation, 57, 163-170.

Biography

EYLER R. COATES

Eyler Coates is an Associate Professor of Engineering Technology at The University of Southern Mississippi in Hattiesburg. He has 12 years of industrial work experience with manufacturers performing industrial engineering functions. He received a B.S. degree in Industrial Engineering (1979), a M.S. degree in Engineering Science (1996), and a Ph.D. in Engineering Science (1998) all from Louisiana State University in Baton Rouge.

\section{S. KANT VAJPAYEE}

Kant Vajpayee is a Full Professor of Engineering Technology at The University of Southern Mississippi in Hattiesburg. He has recently authored the text, "Fundamentals of Economics for Engineering Technologists and Engineers. "His research interests lie in computer-integrated manufacturing, computer aided design / computer aided manufacturing, vibration / noise control. He has a Ph.D. in Mechanical Engineering from the University of Birmingham, England.

\section{JON JUNEAU}

Jon Juneau is an industrial engineering consultant in Hattiesburg, Mississippi. He has 13 years electric utility experience in nuclear fuel management. He has a B.S. degree in Nuclear Engineering (1978), a M.S. degree in Nuclear Engineering (1980) and a M.S. degree in Mathematics (1981) from Texas A\&M University. He has a Ph.D. in Engineering Science (1996) from Louisiana State University. He is a licensed professional engineer and certified in production and inventory management. 